\title{
Design para serviços e a estética sonora no servicescape: influência na experiência estética dos usuários
}

\author{
Design for services and sound aesthetics in the servicescape: influence \\ on the user aesthetics experience
}

COSTA, Humberto

Universidade do Porto I humbertoccosta@gmail.com

SANTOS, Aguinaldo dos

Universidade Federal do Paraná - UFPR I asantos@ufpr.br

\begin{abstract}
Resumo
A presente pesquisa investiga a influência da estética sonora no ambiente de serviço, segundo a ótica do Design para Serviços. A investigação foi norteada pelo seguinte questionamento: como a estética sonora influência na experiência estética dos usuários em um determinado ambiente de serviço? O objetivo principal foi o de demonstrar como a estética sonora influencia na experiência estética dos usuários em um determinado ambiente de serviço. Para atingir os propósitos da pesquisa, foi realizada uma revisão bibliográfica que utilizou duas técnicas: sistemática e narrativa e foi empreendida uma survey com a utilização da ferramenta RPE-Audição. A pesquisa foi realizada em um shopping center presente na cidade de Curitiba, mais exatamente, o Shopping Curitiba. O público-alvo foram os usuários que circulavam pelo ambiente de serviço do referido shopping. A seleção dos participantes se deu por conveniência e somente aqueles com idade superior a 14 participaram. Os resultados obtidos mostraram que a paisagem sonora de um ambiente de serviço influencia na criação e na manutenção de estados de humor, sejam eles positivos ou negativos. Como sugestão para trabalhos futuros, recomenda-se a realização de pesquisas que envolvam outros ambientes de serviço hedônicos para que se possa aprofundar o conhecimento acerca da influência da paisagem sonora na experiência estética dos usuários do serviço.
\end{abstract}

Palavras-chave: Estética sonora. Experiência estética. Servicescape. Design para serviços. Paisagem sonora.

\section{Abstract}

The present research investigates the influence of sound aesthetics on the service environment, from the perspective of Service Design. The investigation was guided by the questioning: how does sound aesthetics influence the user aesthetics experience in a given service environment? The main objective was to demonstrate how sound aesthetics influence the user aesthetics experience. In order to achieve the research purposes, a bibliographic review was performed using two techniques: systematic and narrative. In addition to that, a survey was carried out using the RPE-Hearing tool. The research took place in a shopping mall in the city of Curitiba. The target audience was users in the service environment of said mall. Participants were selected randomly, but they had to be at least 14 years old. Results show that the sound landscape of a service environment influences the creation and maintenance of mood states, whether positive or negative. Future work may include a research involving other hedonic service environments in order to deepen the knowledge about the influence of the sound landscape on the user aesthetics experience of services.

Keywords: Sound aesthetics. Aesthetics experience. Servicescape. Service design. Soundscape. 


\section{INTRODUC̣ÃO}

O setor de serviços tem sido responsável pela geração da maior parcela do Produto Interno Bruto (PIB) das maiores economias do mundo (PINHANEZ, 2009). Contudo, apesar da importância dos serviços na economia, na maior parte das vezes, estes são implementados com base em tentativas e erros (PINHANEZ, 2009). Ainda, constata-se que a produção de conhecimento nas diferentes áreas que compõem a Ciência de Serviços é baixa, especialmente quando comparada com outras áreas de estudo mais tradicionais (SACO; GONÇALVES, 2008).

A abordagem dos serviços pela ótica do Design é recente. De outro lado, os serviços são estudados pela Administração, pelo Marketing e pela Engenharia desde os anos 70. O Design para Serviços apareceu em universidades e consultorias americanas e europeias na década de 90, por meio de organizações como IDEO, UK Design Council e Köln International School of Design (SACO; GONÇALVES, 2008).

A peculiaridade dos Serviços, quando comparados a produtos, tem exigido a geração de conhecimentos específicos no campo do Design (MAGER, 2004). Os profissionais envolvidos com o Design para Serviços necessitam de competências específicas, incluindo cocriação, coparticipação, visão holística do projeto, colaboração multidisciplinar, interatividade (MAGER, 2004; SACO; GONÇALVES, 2008).

A Estética permeia toda a atividade humana e a intensidade de sua presença pode variar. Quando se trata de serviços ou de artefatos, mesmo quando há o predomínio das funções prático-utilitárias, os mesmos, ainda assim, não deixam de proporcionar experiências estéticas aos usuários. Qualquer propriedade de um fenômeno tem potencial para evocar respostas estéticas quando percebida como agradável ou como desagradável pelos sentidos (HECKERT; LEDER, 2008). A dimensão estética se faz presente mediante os sentidos humanos (olfato, tato, palato, visão, audição). Portanto, está diretamente relacionada aos atributos que configuram o serviço.

A relevância do estudo da Estética encontra maior relevância em setores em que a experiência estética dos usuários tem forte impacto em sua satisfação para com o serviço prestado (COSTA, 2017). Esse é o caso dos serviços que são prestados pelos shopping centers, pelo setor hoteleiro, pelo setor de entretenimento, isto para citar alguns exemplos.

A partir do que foi exposto, a questão que norteia esta pesquisa pode ser colocada com o seguinte questionamento: Como a estética sonora influência na experiência estética dos usuários em um determinado ambiente de serviço? A partir da colocação do problema, tem-se como objetivo geral demonstrar 
como a estética sonora influencia na experiência estética dos usuários em um determinado ambiente de serviço. Mais especificamente, pretende-se mapear a experiência estética visceral dos usuários em um ambiente de serviço, pela perspectiva da audição e demonstrar qual seria a o panorama estético ideal da paisagem sonora segunda a perspectiva destes usuários.

É importante ressaltar que a presente pesquisa apresenta algumas delimitações: 1 - a pesquisa situa-se no âmbito do Design e considera os aspectos intangíveis ligados aos Serviços; 2 - apenas um dos sentidos humanos foi mensurado e, portanto, apenas um aspecto da experiência estética dos usuários foi considerado, mais exatamente aquele oriundo da percepção visceral referente à audição; 3 - a pesquisa de campo foi realizada em apenas uma parte do ambiente de serviço da instituição parceira da pesquisa e 4 - a perspectiva estética adotada está consonante com aquela adotada em estudos da área do Design para serviços e, portanto, mais ligada à acepção grega do termo Estética.

\section{DESIGN PARA SERVIC̣OS E A ESTÉTICA SONORA NO AMBIENTE DE SERVIC̣O}

\subsection{Os Serviços o Design Para Serviços}

Entende-se que os serviços dizem respeito a uma prestação de algo que alguma pessoa desempenha para a utilidade, satisfação ou suporte da atividade de outra pessoa (PACENTI, 2004). Assim, a oferta de serviços está fundamentada no provimento de ações e experiências e estas têm por propósito entregar os benefícios a alguém. O resultado final de um serviço pode ser a satisfação do usuário com a oferta do resultado desejado (HOLMILD; EVENSON, 2008), a solução de problema(s) ou benefício(s) para o(s) usuário(s) (ZEITHAML; BITNER; GREMLER, 2011).

Os serviços são, simultaneamente, uma transação econômica e uma transação de sentido (COSTA, 2017). Isto é, o valor dos serviços para o usuário é sempre uma combinação de elementos funcionais (o benefício obtido em termos de utilidade) e elementos emocionais (ligados à experiência, às sensações, aos benefícios intangíveis desfrutados durante a utilização do serviço). Por pertencer ao domínio da construção de sentido, os serviços podem ser vinculados ao Design (FREIRE, 2011). Assim nasceu uma nova abordagem no campo do Design, denominada Design para Serviços (Service Design).

A literatura consultada mostra que não há uma definição única e consensual para tal termo. Para os propósitos do presente trabalho, entende-se que o Design para Serviços abrange o projeto de toda a experiência do serviço, 
bem como o projeto do processo e das estratégias para entregá-lo (MORITZ, 2005; STICKDORN; SCHENEIDER, 2010). Nessa direção, o Design para Serviço deve abordar a forma e a funcionalidade dos serviços a partir do ponto de vista dos usuários e deve ter dois objetivos bem delineados: com relação ao usuário, - Design para Serviço deve garantir que as interfaces de serviços sejam úteis, utilizáveis e desejáveis. Já com relação ao provedor do serviço, o Design para Serviço deve garantir que as interfaces de serviços sejam eficazes, eficientes e distintas (MAGER, 2004, 2007).

O ponto central do Design para Serviços é o de compreender o valor e a natureza das relações entre pessoas e pessoas, entre pessoas e coisas, entre pessoas e organizações e entre organizações de diversos tipos (COSTA, 2017). Na relação entre pessoa-organizações já há arcabouço teórico-prático, oriundo do Marketing (COSTA, 2017; FREIRE, 2011). Da relação pessoa-pessoa têm-se os conhecimentos oriundos da Antropologia, Psicologia e Sociologia. Com relação ao Design, este tem dedicado esforços para compreender a relação ser humanoartefatos, que é apenas um dos elos desta equação (COSTA, 2017). Portanto, há de se buscar uma abordagem holística que envolva a participação de diversas outras áreas do saber humano e, neste ponto, dada à natureza multidisciplinar do Design, tal tarefa é mais fácil, uma vez que a multidisciplinaridade é a tônica da atividade do designer.

\subsection{A Estética e a Estética nos Serviços}

De acordo com a acepção grega, Estética denota sensação, sentimento, estesia (ROSENFIELD, 2009). Nesse ínterim, também é tarefa da Estética analisar o complexo das emoções e dos sentimentos humanos, investigando "[...] sua integração nas atividades físicas e mentais do homem, debruçando-se sobre as produções (artísticas ou não) da sensibilidade, com o fim de determinar suas relações com o conhecimento, a razão e a ética." (ROSENFIELD, 2009, p. 7). Todavia, para os propósitos do Design para Serviços, a Estética tem de ser abordada por uma acepção mais ampla, ou seja, como experiência integradora da percepção sensorial, comportamental e reflexiva vivenciada por um indivíduo. Isso quer dizer que a Estética envolve um tipo de experiência humana que se inicia com a percepção sensorial de um fenômeno (nível sensorial), que transforma a paisagem corporal (nível comportamental) e culmina em uma significação acerca de toda a experiência vivenciada (nível reflexiva) (COSTA, 2017). Essa experiência provoca ou afirma um determinado estado afetivo, podendo ser este prazeroso ou não. Todavia, uma experiência estética completa só ocorrerá se houver uma integração das percepções oriundas de cada um dos níveis. Caso isso não aconteça, o indivíduo terá uma experiência estética parcial, mas independentemente, um estado afetivo será evocado ou (re) afirmado e culminará na criação ou no reforço de um estado de humor (COSTA, 2017). 
O entendimento acerca da Estética aqui adotado leva à constatação de que o mundo é o lugar da Estética. Assim, uma obra de arte, um som, uma rua suja, uma vestimenta, um gesto corporal, um tom de voz empregado no atendimento ao cliente, a imagem de uma instituição etc., são fenômenos passíveis de despertar uma experiência estética naquele que percebe tal fenômeno.

Tem-se, então, a dimensão Estética e esta permeia toda a atividade humana, sendo que a intensidade de sua presença é bastante variável (COSTA, 2017). No âmbito dos serviços ou dos artefatos, mesmo quando há o predomínio das funções prático-utilitárias, há o desencadeamento de experiências estéticas nos usuários. Qualquer propriedade de um fenômeno pode evocar uma resposta estética, quando percebida como agradável ou como desagradável em cada uma das dimensões (COSTA, 2017). No entanto, constata-se que mesmo sensações desagradáveis se enquadram dentro dessa resposta estética, sendo o desagradável compreendido como parte da escala do que se pode considerar "belo" (COSTA, 2017).

No nível dos sentidos, a percepção estética está diretamente ligada aos atributos que configuram um serviço, atributos estes que dependem de suas características que podem despertar níveis variados de prazer/desprazer. Dessa forma, há um amplo espaço para interpretações individualizadas, tendo em vista que cada um desses sentidos funciona de modo subjetivo e envolve juízos de valor (CONSIGLIERI, 2000; QUEIROZ, 2011).

No âmbito do Design para Serviços, a dimensão Estética assume um nível de complexidade maior, pois são acrescidos os aspectos relacionais entre os seres humanos, elementos estes muitas vezes determinantes da qualidade da experiência de um serviço como um todo. Ademais, a complexidade pode ser aumentada graças aos vários pontos de contato, mutualmente influentes nas percepções estéticas do usuário. O desafio será o de projetar adequadamente as interfaces para que elas proporcionem ao indivíduo, uma experiência estética integradora. Constata-se assim, que a implantação de uma intenção estética por uma instituição acerca do serviço que presta é afetada por um número mais amplo de variáveis do que aquele observado na análise de artefatos isolados, o que demanda o emprego de um processo de avaliação constante para que se tenha um panorama atualizado acerca da estética do serviço prestado (COSTA, 2017).

\subsubsection{Estética e afetividade}

Abordar a Estética por uma perspectiva ampliada envolve a compreensão acerca da afetividade humana, aqui considerada como sendo composta por emoções, sentimentos e estado de humor. Segundo Goleman (1995), Damásio 
(2004, 2011), Ledoux (2001) e Morin (2005), a afetividade foi ignorada pelos estudos e pesquisas até recentemente. Todavia, a força e a complexidade dos acontecimentos contemporâneos têm promovido consideráveis mudanças nesse cenário, haja vista a necessidade de se compreender o homem por uma perspectiva holística e integradora (DAMÁSIO, 2004, 2011).

A afetividade intervém no desenvolvimento e nas manifestações da racionalidade, sendo aquela, capaz de extraviar, obscurecer, animar ou estimular o pensamento (MORIN, 2005). O homem "[...] é capaz de considerar racionalmente a realidade que o cerca", todavia "o princípio da racionalidade só dá uma radiografia da realidade; não lhe dá substância $[\ldots]$ ", isso porque "[...] o racional comporta o cálculo, a lógica, a coerência, a verificação empírica, mas não o sentimento de realidade." MORIN, 2005, p. 121).

Tomando o humano como um organismo indivisível, é impossível a separação entre afetividade e racionalidade. Frente a um fenômeno, ambos processam os dados para que a melhor decisão seja tomada (DAMÁSIO, 2004; NORMAN, 2008). As decisões tomadas consideram os dados racionais e afetivos. De outro lado, a afetividade também podem ser fontes de problemas. Isso pode acontecer "[...] quando o medo se transforma em ansiedade, o desejo dá lugar à ganância, uma contrariedade converte-se em raiva e a raiva em ira; a amizade dá lugar à inveja e o amor à obsessão, ou o prazer se torna um vício [...]" (LEDOUX, 2001, p. 19). Percebe-se, então, que a afetividade pode gerar consequências tanto úteis quanto patológicas para o ser humano (LEDOUX, 2001, p. 19).

A afetividade diz respeito a um complexo sistema de julgamentos que incluem as emoções, os sentimentos e os estados de humor. A emoção é um estado afetivo intencional e agudo, está relacionado a um estímulo específico e tem duração definida no tempo. Para os propósitos desta pesquisa, tal característica mostra-se promissora, pois o usuário vivencia as emoções durante a jornada do Serviço. Após um estímulo que dispara uma emoção, o próximo passo é a vivência da emoção em relação ao estímulo que a desencadeou e a percepção da relação entre o estímulo e o estado emocional do corpo (DAMÁSIO, 2004). Os sentimentos são processos conscientes e têm repertório diferente de pensamentos, de reações e de memórias. São revelações do estado da vida dentro do organismo (DAMÁSIO, 2004). As emoções "[...] são ações ou movimentos, muitos deles públicos, que ocorrem no rosto, na voz ou em comportamentos específicos" (DAMÁSIO, 2004, p. 35), podendo ser observáveis do ponto de vista de outro indivíduo (a expressão facial, o ritmo dos movimentos corporais etc.).

O humor é um estado mais duradouro (horas, dias), sendo caracterizado por ser global, ou seja, não é necessariamente desencadeado por um único estímulo como é comum no caso da emoção (DAMÁSIO, 2004, 2011). O estado de humor geralmente se altera ao longo do tempo, junto aos sentimentos 
associados com emoções mais breves, que se sobrepõem e interagem com eles (DAMÁSIO, 2006, 2011; NORMAN, 2008). A percepção Estética interfere na geração do estado de humor, sendo que este também tem potencial para interferir nas futuras percepções do indivíduo, no decorrer de sua jornada.

\subsection{A Percepção Estética Sensorial Evocada Pela Audição}

Um dos componentes do espectro de matizes do sistema sensorial humano são compostos pelos sons (SCHAFER, 2011). O ser humano utiliza os sons não só para comunicar, mas também para interpretar e expressar sua percepção estética em relação ao mundo ao seu redor (LAUKKA, 2007). Os sons são capazes de influenciar diretamente os aspectos afetivos, evocando emoções e sentimentos positivos e/ou negativos naquele que o percebe (ACKERMAN, 1992).

Segundo a literatura especializada (ACKERMAN, 1992; GURNEY, 1880; LAUKKA, 2007; LEVINSON, 1990), os sons têm potencial para induzir o ouvinte com relação à tomada de decisões ou influenciar seu comportamento. Por exemplo: há certa preferência por parte das pessoas em consumir alimentos crocantes e que provocam um ruído agradável, sendo tais atributos, características importantes no processo de venda de tais alimentos (ACKERMAN, 1992; LEVINSON, 1990).

A diversidade de sons presentes em um determinado ambiente forma uma "paisagem sonora" (SCHAFER, 2011). Segundo Truax (1996 apud SANTOS, 2006), o que caracteriza a composição de uma determinada paisagem sonora é a presença de sons ambientais em contextos reconhecíveis.

Dentre os sons possíveis que um usuário pode encontra, ao longo da jornada de sua experiência em um serviço, destaca-se a música e esta desempenha um papel proeminente. $O$ homem tem suas pupilas dilatadas e o nível de endorfina aumentado quando canta. Pacientes acamados reagem à música e crianças autistas ou com incapacidade para aprender, frequentemente apresentam menos dificuldade para se comunicarem através da música. Além de animar, a música encoraja sedentários a exercitarem-se (AKERMAN, 1992).

\subsection{As Evidências Relevantes Para a Estética do Serviço}

As evidências físicas constituem o ambiente (também chamado de servicescape) onde o serviço é executado e onde usuários e prestador do serviço interagem (ZEITHAML; BITNER; GREMLER, 2011). Incluso no conceito "ambiente de serviço" estão, por exemplo, todos os atributos exteriores, 
como sinalização, estacionamento e paisagismo etc. Quanto aos atributos interiores, estes são compostos pelo leiaute do espaço, os equipamentos, os colaboradores, a decoração, a iluminação, os aromas, os sons, a temperatura, a cortesia, o cuidado, a empatia etc.

A importância do ambiente de serviço depende da natureza do serviço e da experiência de consumo. Com relação aos comportamentos no ambiente de serviço, sabe-se que o ser humano é influenciado pelas instalações físicas. Segundo Bitner (1992), os usuários respondem, do ponto de vista comportamental, de duas formas: aproximação e evasão. Os comportamentos de aproximação são aqueles relacionados ao desejo de permanecer, de explorar, o prazer em comprar, em retornar ao estabelecimento, de gastar dinheiro etc. Já os comportamentos de evasão constituem o oposto.

O ambiente de serviço também pode ter influência no grau de sucesso da experiência dos usuários ao executarem seus planos no local (LOVELOCK; WIRTZ; HEMZO, 2011). Cada indivíduo vai até uma organização de serviço, com um objetivo, que pode ser apoiada ou não pelas instalações. Com relação às interações sociais, sabe-se que o ambiente de serviço influencia na qualidade e na natureza das interações entre usuários e prestadores de serviço. Segundo Bitner (1992), todas as interações sociais são diretamente afetadas pelo ambiente de serviço, sendo que este também afeta a natureza da interação social quanto à duração e à progressão real dos eventos. As variáveis ambientais como a paisagem sonora, a disposição do mobiliário, as dimensões espaciais etc., podem definir até os limites de eventos sociais entre usuários e colaboradores (FORGAS, 1979 apud BITNER, 1992).

Os elementos percebidos no ambiente de serviço têm potencial para induzir respostas estéticas, as quais podem influenciar comportamentos. As qualidades dos ambientes são de duas dimensões: prazer/desprazer e grau de entusiasmo (BITNER, 1992). Os ambientes estimulantes são vistos positivamente, a não ser que o entusiasmo esteja combinado com algo desagradável, como o excesso de ruídos, os quais poderão ser evitados por algumas pessoas (ZEITHAML; BITNER; GREMLER, 2011).

As respostas afetivas ao ambiente de serviço podem ser transferidas às pessoas e/ou aos objetos que ali estão. Na pesquisa de Obermiller e Bitner (1984 apud BITNER, 1992), usuários que viram produtos de varejo em um ambiente esteticamente agradável avaliaram tais produtos de forma mais positiva do que aqueles que viram os mesmos produtos em um ambiente desagradável. Disso, vê-se que as percepções das pessoas, acerca do ambiente de serviço, parecem ter influenciado sentimentos aparentemente não relacionados aos produtos, mas a um aspecto do serviço. 


\subsection{Consumo Hedônico}

As primeiras pesquisas sobre a abordagem hedônica do consumo foram divulgadas nos idos da década de 80 (HIRSCHMAN; HOLBROOK, 1982). O entendimento apresentado por Hirschman e Holbrook (1982) apresenta as características psicológicas, emocionais, inconscientes e simbólicas do consumo. De acordo com Hirschman e Holbrook (1982), há duas perspectivas que são utilizadas para englobar o consumo: 1) tradicional: trata das características utilitárias, tangíveis, econômicas, conscientes, cognitivas e objetivas do consumo, entendendo-o pelo viés utilitário. Nessa perspectiva, a objetividade de serviços/produtos pauta-se em critérios que estão baseados nas funcionalidades destes serviços/produtos; 2 ) hedônica: se refere ao prazer experimentado ou antecipado no ato do uso/compra de um serviço ou produto.

O consumo hedônico abrange os aspectos que são vinculados às características fantasiosas, emocionais e multissensoriais na interação do usuário com serviços/produtos, tendo como corolário uma experiência de fantasia, divertimento, estímulos sensoriais e prazer, que são vivenciados no momento do consumo e com a finalidade voltada em si mesmo.

É importante reter que o consumo abrange ambas as categorias de motivação e valoração (ADDIS; HOLBROOK, 2001) e uma perspectiva não exclui a outra. O que diferencia é o relevo que se dá a uma das categorias. No entender de Ahtola (1985), em determinadas circunstâncias, alguns comportamentos estão carregados de motivações mais hedônicas que utilitárias. Em outros momentos, o peso inverte. Por exemplo, se os aspectos subjetivos do serviço forem prestigiados, vê-se que o cliente está tendendo para o lado hedonista, uma vez que privilegiam características psicoemocionais, tais como emoções, sentimentos e prazer, todos estes como um fim em si mesmo (AHTOLA, 1985). De outro lado, se aspectos relacionados com o valor de uso receberem maior relevo, o viés utilitário terá maior peso.

\section{MÉTODOS E TÉCNICAS}

A presente pesquisa apresenta uma abordagem qualitativa, é de natureza aplicada e exploratória (CRESWELL; CLARK, 2013; GRAY, 2012). Quanto aos procedimentos, utilizou-se a revisão bibliográfica e realizou-se uma survey com o propósito de levantar informação diretamente com um grupo de interesse, a respeito dos dados que se desejava obter.

Para a realização da revisão bibliográfica, duas técnicas foram utilizadas: sistemática e narrativa, sendo que a segunda complementou a primeira. A revisão bibliográfica sistemática (RBS) foi utilizada por ser um método explícito, 
planejado e justificável (DRESCH; LACERDA; ANTUNES JUNIOR, 2015). Para a sua realização, seguiu-se as orientações de Conforto, Amaral e Silva (2011).

Segundo Gray (2012), a pesquisa com survey é um procedimento útil em pesquisas exploratórias, em que se intenta a obtenção de dados sobre as opiniões e características de determinado grupo de pessoas. Para a coleta de dados, foi utilizada a "Roda de Percepção Estética - Audição", RPEAudição, desenvolvida por Costa (2017). As orientações para a aplicação dos instrumentos e para as análises dos dados foram seguidas conforme aponta Costa (2017).

A presente pesquisa foi realizada tendo o Shopping Curitiba como instituição parceira da pesquisa. O público-alvo foram os frequentadores do shopping supramencionado. Os respondentes foram escolhidos aleatoriamente, sem distinção de gênero e somente aqueles com idade superior a 14 anos foram abordados. Ao todo, 150 respondentes preencheram as RPE-Audição.

\section{ANÁLISE DOS DADOS E INTERPRETAC̣ÃO DOS RESULTADOS}

\subsection{Contexto do Estudo}

Segundo a Associação Brasileira de Shopping Centers, ABRASCE, há 561 Shopping Centers no Brasil, com mais de 98.200 lojas, que geram cerca de 1.024.808 de empregos diretos. Em 2016, tais estabelecimento faturaram, juntos, 157,9 bilhões de reais, contando com a visita de 438,675 milhões de pessoas (ABRASCE, 2017). Na capital paranaense, há 14 shopping centers de grande porte em funcionamento.

Localizado na região central de Curitiba, o Shopping Curitiba foi inaugurado em 26 de setembro de 1996. Atualmente conta com 134 lojas divididas em 4 pavimentos, 6 salas de cinema e 1069 vagas de estacionamento. Recebe, mensalmente, cerca de 750 mil visitantes e destes, $22 \%$ pertencem à classe $A, 58 \%$ à classe $B$ e $20 \%$ à classe C (ABRASCE, 2017).

\subsection{Realização do Estudo e Seleção dos Participantes}

No dia seis de maio de 2017, foi realizada nas dependências do Shopping Curitiba, uma survey com a aplicação da "Roda de Percepção Estética - Audição" (COSTA, 2017), com o intuito de coletar dados acerca da percepção estética visceral evocada pela paisagem sonora nos usuários (respondentes). Uma equipe composta por 6 entrevistadores, abordaram 150 pessoas que estavam distribuídas pelos 4 pisos do empreendimento. 
Os usuários eram selecionados por conveniência, ou seja, foram escolhidos aqueles que estavam disponíveis, sem qualquer tipo de distinção. A única restrição aplicada para a participação na pesquisa era de que os usuários tivessem idade igual ou superior a quatorze anos, pois seria necessário que os respondentes estivessem familiaridade com os termos presentes na RPEAudição. Uma vez que aceitavam participar da pesquisa, os usuários eram questionados acerca das emoções que eles tinham vivenciado e que foram evocadas pela paisagem sonora do ambiente de serviço. Também, foram questionados acerca de quais emoções gostariam de vivenciar no mesmo ambiente.

\subsection{A Percepção Estética Visceral Evocada Pela Audição}

Observou-se que no ambiente de serviço do Shopping Curitiba, há iniciativas para se criar uma "paisagem sonora" com o intuito de despertar e de reforçar estados de humor positivos nos usuários, com contribuições diretas em sua jornada pelo serviço. Tal constatação é decorrente da constatação, via observação direta, da presença de sonorização ambiente, a não incidência de sons marcantes e desagradáveis, sejam eles oriundos de fontes externas ou internas. Há, ainda, a incidência de sons gerados dos próprios usuários. De forma geral, pode-se dizer que a paisagem sonora do ambiente de serviço analisado é, do ponto de vista auditivo, pouco ruidoso.

A Tabela 1 apresenta a frequência e a intensidade das emoções que, segundo os resultados da survey realizada com os usuários, são evocadas a partir da paisagem sonora presentes no ambiente de serviço do Shopping Curitiba. A referida tabela também apresenta a frequência e a intensidade com que cada uma das emoções é esperada no mesmo ambiente de serviço.

De acordo com Tabela 1, nota-se que há um predomínio de emoções positivas evocadas nos usuários, no ambiente de serviço analisado, do ponto de vista da audição. A experiência estética dos usuários, em meio a 10 emoções mais vivenciadas, está pautada em oito emoções positivas, as quais apresentam gradações altas (4, 5 ou 6). Em média, 23\% dos respondentes disseram ter vivenciado emoções como tranquilidade, animação, felicidade, divertimento e serenidade em altas gradações (4, 5 ou 6). Isso aponta para uma experiência estética positiva.

Em um ambiente de serviço voltado para o consumo hedônico, como é o caso do ambiente que foi analisado, é importante que emoções positivas sejam evocadas. As emoções positivas são fundamentais para a criação e/ou reforço de estados de humor positivos. De acordo com a literatura consultada, a criação e o reforço de estados de humor positivos proporcionam uma experiência estética também positiva aos usuários, durante sua jornada pelo 
serviço. Certamente, isso influenciará na construção de uma imagem positiva acerca do estabelecimento. Ainda, infere-se que estados de humor positivos têm potencial para conduzir o usuário a consumir, o que seria muito interessante para o estabelecimento. Em uma cidade com vários estabelecimentos voltados para o consumo hedônico, infere-se que aqueles que proporcionarem melhores experiência aos usuários, serão aqueles com maior possibilidade de atrair ainda mais consumidores.

Tabela 1 - Gradação das emoções sentidas e emoções esperadas no ambiente de serviço do Shopping Curitiba, segundo a percepção estética evocada pela audição.

\begin{tabular}{lccccccccc}
\hline \multirow{2}{*}{$\begin{array}{l}\text { Emoção } \\
\text { (Audição) }\end{array}$} & $\begin{array}{c}\text { Gradação } \\
\text { Sentida }\end{array}$ & $\begin{array}{c}\text { Gradação } \\
\text { Esperada }\end{array}$ & $\mathbf{0}$ & $\mathbf{1}$ & $\mathbf{2}$ & $\mathbf{3}$ & $\mathbf{4}$ & $\mathbf{5}$ & $\mathbf{6}$ \\
\hline Feliz & 196 & 244 & 109 & 0 & 1 & 5 & 9 & 13 & 13 \\
\hline Entusiasmado & 79 & 148 & 133 & 1 & 0 & 0 & 5 & 8 & 3 \\
\hline Animado & 209 & 170 & 105 & 1 & 1 & 2 & 16 & 14 & 11 \\
\hline Sereno & 104 & 126 & 127 & 3 & 1 & 0 & 3 & 9 & 7 \\
\hline Divertido & 117 & 181 & 123 & 0 & 3 & 2 & 11 & 5 & 6 \\
\hline Tranquilo & 284 & 281 & 88 & 1 & 3 & 3 & 22 & 18 & 15 \\
\hline Admirado & 38 & 82 & 140 & 1 & 2 & 1 & 3 & 0 & 3 \\
\hline Afetuoso & 53 & 22 & 139 & 0 & 0 & 1 & 4 & 2 & 4 \\
\hline Estimulado & 74 & 71 & 134 & 0 & 0 & 4 & 2 & 6 & 4 \\
\hline Inspirado & 77 & 143 & 133 & 0 & 1 & 1 & 5 & 8 & 2 \\
\hline Meditativo & 27 & 12 & 142 & 1 & 0 & 3 & 3 & 1 & 0 \\
\hline Melancólico & 25 & 3 & 142 & 1 & 1 & 3 & 2 & 1 & 0 \\
\hline Nervoso & 53 & 1 & 135 & 3 & 2 & 2 & 2 & 4 & 2 \\
\hline Sentimental & 32 & 31 & 142 & 1 & 0 & 1 & 4 & 0 & 2 \\
\hline Comovido & 6 & 3 & 146 & 2 & 2 & 0 & 0 & 0 & 0 \\
\hline Impaciente & 81 & 4 & 127 & 1 & 3 & 8 & 8 & 0 & 3 \\
\hline Nostálgico & 40 & 45 & 140 & 0 & 2 & 2 & 2 & 2 & 2 \\
\hline Arrepiado & 8 & 1 & 145 & 2 & 3 & 0 & 0 & 0 & 0 \\
\hline Entristecido & 4 & 1 & 147 & 2 & 1 & 0 & 0 & 0 & 0 \\
\hline Tenso & 76 & 5 & 131 & 3 & 1 & 0 & 7 & 5 & 3 \\
\hline & & & & & & & & & \\
\hline
\end{tabular}

Fonte: Os autores, com base na pesquisa realizada (2017).

De outro lado, constata-se na Tabela 1, que emoções negativas também foram evocadas nos usuários pela paisagem sonora do ambiente de serviço analisado. Emoções como impaciência e tensão foram as mais vivenciadas. Em se tratando de um ambiente hedônico, a presença de tais emoções mostra-se preocupante. Embora a literatura tenha apontado a quase impossibilidade de experiências estéticas totalmente positivas ou totalmente negativas, as emoções negativas deveriam estar em um patamar muito abaixo do que foi constatado, ainda que não tenha sido encontrada na literatura, uma relação de proporcionalidade ideal. Tal afirmação decorre de uma inferência de que um panorama estético negativo contribui para a geração/reforço de estados de humor também negativos. 
Por essa perspectiva, pessoas com estado de humor negativo tendem a se retrair e a evitar qualquer tipo de aproximação. Em se tratando de consumo, tal comportamento não é desejado.

Com a survey realizada, foi possível constatar que os respondentes, embora tenham tido uma experiência positiva, estes desejam que tal experiência seja ainda mais positiva. Por exemplo, na Tabela 1, pode-se ver que eles desejam que a experiência evocada pela paisagem sonora seja ainda mais tranquila, feliz, divertida, animada e serena. De outro lado, desejam que o panorama estético negativo seja minimizado. Por exemplo, desejam sentir menos impaciência, menos tensão, menos nervosismo, menos melancolia etc.

Com base na pesquisa realizada, entende-se que a direção do Shopping Curitiba necessita buscar maneiras de melhorar o panorama estético evocado pela paisagem sonora em seus usuários. O reforço de uma experiência estética positiva trará ganhos para as atividades diretamente ligadas ao consumo, como é o caso das lojas e quiosques e, também, contribuirá na criação de uma imagem (branding) positiva junto aos usuários. A literatura apontou que as experiências estéticas, sejam elas positivas ou negativas, influenciam diretamente na construção da imagem que o usuário faz de um determinado estabelecimento.

\section{CONSIDERAC̣̃̃ES FINAIS}

De acordo com os dados coletados e as análises efetuadas, constatouse que a paisagem sonora de um ambiente de serviço influencia na experiência estética dos usuários em um ambiente de serviço. No caso da percepção estética auditiva, os elementos não tangíveis que compõem a paisagem sonora são responsáveis por evocar emoções e sentimentos que podem criar ou potencializar estados de humor positivos ou negativos.

A pesquisa constatou que a paisagem sonora do ambiente de serviço analisado evoca emoções positivas nos usuários. A maioria dos respondentes disseram ter vivenciado emoções positivas como tranquilidade, animação, felicidade, divertimento e serenidade em altas gradações. Em um ambiente de serviço voltado para o consumo hedônico, como é o caso do ambiente que foi analisado, é importante que emoções positivas sejam evocadas, pois podem criar ou reforçar estados de humor também positivos. Tal cenário pode potencializar o consumo, bem como interferir na criação de uma imagem positiva acerca do estabelecimento, por parte do usuário do serviço.

De outro lado, a pesquisa também detectou que a paisagem sonora do ambiente de serviço analisado também evoca emoções negativas, mas no caso analisado, em proporções baixas. Tal cenário se mostra preocupante, pois um panorama estético negativo contribui para a geração ou o reforço de estados 
de humor também negativos. Por essa perspectiva, os usuários tendem a se retrair e a evitar qualquer tipo de aproximação. Em se tratando de consumo, tal comportamento não é desejado.

A pesquisa também mostrou que os usuários, embora tenham vivenciado uma experiência estética positiva, esperam que a mesma seja ainda mais positiva e que emoções esteticamente negativas sejam minimizadas drasticamente.

Com base na presente pesquisa e do ponto de vista do Design para Serviços, sugere-se que a administração do Shopping Curitiba aprofunde o conhecimento acerca do público que frequenta utiliza seus serviços e, com base nesses dados, elabore diretrizes estéticas para nortear as futuras soluções de melhorias da experiência estética dos usuários. Outra sugestão seria o envolvimento dos usuários e de diferentes stakeholders na criação de soluções com vistas a melhorar a experiência estética sonora vivenciada no ambiente de serviço. É importante ter em vista que compreender o usuário do serviço deve ir além de descrições estatísticas e análises empíricas de suas necessidades. Deve-se buscar compreender suas experiências individuais com o serviço, bem como o contexto mais abrangente de suas particularidades. Ao conhecer e compreender a cultura, os hábitos, as motivações e o contexto social de seus usuários e stakeholders, bem como envolvê-los profundamente na exploração e na definição das soluções de melhorias do serviço, há maior possibilidade de se criar serviços com alto valor agregado e que dificilmente serão copiados pela concorrência.

Como sugestão para trabalhos futuros, recomenda-se a realização de pesquisas que envolvam outros ambientes de serviço hedônicos para que se possa aprofundar o conhecimento acerca das possíveis influências da paisagem sonora na experiência estética dos usuários do serviço. 


\section{REFERÊNCIAS}

ACKERMAN, Diane. Uma história natural dos sentidos. São Paulo: Bertrand Brasil, 1992.

ADDIS, Michela; HOLBROOK, Morris B. On the conceptual link between mass customization and experiential consumption: an explosion of subjectivity. Journal of Consumer Behaviour, London, v. 1, n. 1, p. 50-60, 2001. Disponível em: http://onlinelibrary.wiley.com/doi/10.1002/cb.53/pdf. Acesso em: 10 dez. 2016.

AHTOLA, Olli T. Hedonic and utilitarian aspects of consumer behaviour: an atitudinal perspective. Advances in Consumer Research, v. 12, p. 7-10, 1985. Disponível em: http://www.acrwebsite.org/volumes/6348/volumes/v12/NA12. Acesso em: 10 dez. 2016.

ABRASCE - ASSOCIAC̣ÃO BRASILEIRA DE SHOPPING CENTERS. Disponível em: http://www.abrasce.com.br/. Acesso em: 17 jul. 2017.

BITNER, Mary Jo. Servicescapes: the impact of physical surroundings on customers and employees. Journal of Marketing, Chicago, v. 56, n. 2, p. 57-71, 1992.

CONFORTO, Edivandroi Carlos; AMARAL, Daniel Capaldo; SILVA, Sérgio Luis. Roteiro para revisão bibliográfica sistemática: aplicação no desenvolvimento de produtos e gerenciamento de projetos. In: CONGRESSO BRASILEIRO DE GESTÃO DE DESENVOLVIMENTO DE PRODUTO., 8., 2011, Porto Alegre. Anais [...]. Porto Alegre, 2011. Disponível em: http://www.ufrgs.br/cbgdp2011/ downloads/9149.pdf. Acesso em: 14 dez. 2016.

CONSIGLIERI, Victor. As significações da arquitetura. Lisboa: Estampa, 2000.

COSTA, Humberto. Design para serviços e consistência estética: proposição de um protocolo de avaliação estética em serviços. 2017. 462 f. Tese (Doutorado em Design) - Setor de Artes, Comunicação e Design, Universidade Federal do Paraná, Curitiba, 2017.

CRESWELL, John W:; CLARK, Vicki L. Plano. Pesquisa de métodos mistos. 2. ed. Tradução de Magda F. Lopes. Porto Alegre: Penso: 2013.

DAMÁSIO, António. E o cérebro criou o homem. São Paulo: Companhia das Letras, 2011. 
DAMÁSIO, António. Em busca de Espinosa: prazer e dor na ciência dos sentimentos. São Paulo: Companhia das Letras, 2004.

DAMÁSIO, António. O mistério da consciência. São Paulo: Companhia das Letras, 2006.

DRESCH, Aline; LACERDA, Daniel Pacheco; ANTUNES JUNIOR, José Antonio Vale. Design science research: método de pesquisa para avanço da ciência e tecnologia. Porto Alegre: Bookman, 2015.

FREIRE, Karine de Mello. Design de serviços, comunicação e inovação social. 2011. Tese (Doutorado em Design) - Pontifícia Universidade Católica, Rio de Janeiro, 2011.

GOLEMAN, Daniel. Inteligência emocional. 47. ed. São Paulo: Objetiva, 1995.

GRAY, David E. Pesquisa no mundo real. 2. ed. Porto Alegre: Penso, 2012.

GURNEY, Edmund. The power of sound. London: Smith, Elder, 1880.

HEKKERT, Paul; LEDER, Helmut. Product aesthetics. In: SCHIFFERSTEIN, Hendrik N. J.; HEKKERT, Paul. (ed.). Product experience. San Diego, CA: Elsevier, 2008. p. 259-285.

HIRSCHMAN, Elizabeth C.; HOLBROOK, Morris B. Hedonic consumption: emerging, concepts, methods and propositions. Journal of Marketing, Chicago, n. 46, p. 92-101, 1982.

HOLMLID, Stefan; EVENSON, Shelley. Bringing service design to service sciences, management and engineering. In: HEFLEY, Bill; MURPHY, Wendy. Service science, management and engineering education for the 21st century: part 3. New York: Springer, 2008. p. 341-345.

LAUKKA, Petri. Uses of music and psychological well-being among the elderly. Journal of Happiness Studies, Dordrecht, v. 8, p. 215-241, 2007.

LEDOUX, Joseph. O cérebro emocional. Rio de Janeiro: Objetiva, 2001.

LEVINSON, Jerrold. Music and the negative emotions. In: LEVINSON, Jerrold. Music, art, \& metaphysics. Ithaca: Cornell University. 1990. p. 306-335. 
LOVELOCK, Christopher; WIRTZ, Jocken; HEMZO, Miguel Angelo. Marketing de serviços: pessoas, tecnologia e estratégia. 7. ed. São Paulo: Pearson, 2011.

MAGER, Birgit. Service design. In: ERLHOFF, Michael; MARSHALL, Tim (ed.). Design dictionary: perspectives on design terminology. Boston: Birkhäuser, 2007.

MAGER, Birgit. Service design: a review. Cologne: Köln International School of Design, 2004.

MORIN, Edgar. O método 5: a humanidade da humanidade. 3. ed. Porto Alegre: Sulina, 2005.

MORITZ, Stefan. Service design: pratical access to an evolving field. London: Köln International School of Design, University of Applied Sciences Cologne, 2005.

NORMAN, Donald A. Design emocional. Rio de Janeiro: Rocco, 2008.

PACENTI, Elena. Design dei servizi. In: BERTOLA, Paola; MANZINI, Ezio (ed.). Design multiverso: appunti di fenomenologia del design. Milano: Edizioni POLI. design, 2004. p. 151-164.

PINHANEZ, Claudio. Services as customer-intensive systems. 2009.

Disponível em: http://www.mit.org/10.1162/desi.2009.25.2.3. Acesso em: 20 mar. 2017.

QUEIROZ, Shirley Gomes. A dimensão estético-simbólica dos produtos na relação afetiva com usuários. 2011. 230f. Tese (Doutorado em Engenharia de Produção) - Programa de Pós-Graduação em Engenharia de Produção, Universidade Federal de Santa Catarina, Florianópolis, 2011.

ROSENFIELD, Kathrin H. Estética. Rio de Janeiro: Jorge Zahar, 2009.

SACO, Roberto M.; GONCALVES, Alexis P. Service design: an appraisal. Design Management Review, Boston, v. 19, n. 1, p. 10-19, 2008.

SANTOS, Fátima Carneiro dos. A paisagem sonora, a criança e a cidade. 2006. Tese (Doutorado em Música) - Universidade Estadual de Campinas, Campinas, 2006.

SCHAFER, Murray. O ouvido pensante. 2. ed. São Paulo: Ed. UNESP, 2011. 
STICKDORN, Marc; SCHNEIDER, Jakob. This is service design thinking: basics, tools, cases. Amsterdam: BIS Publishers, 2010.

ZEITHAML, Valarie A.; BITNER, Mary Jo; GREMLER, Dwayne D. Marketing de serviços: a empresa com foco no cliente. Porto Alegre: Bookman, 2011.

Data de submissão: 2018-08-17

Data de aceite: $2018-09-20$ 